\title{
Maturation of Ventilatory Responses to 1-Minute Exercise
}

\author{
YAACOV ARMON, DAN MICHAEL COOPER, AND STEFANIA ZANCONATO \\ Division of Respiratory and Critical Care, Department of Pediatrics, Harbor-UCLA Medical Center, \\ Torrance, California 90509
}

\begin{abstract}
To test the hypothesis that ventilatory responses to exercise mature during growth in healthy children, we examined $\mathrm{CO}_{2}$ production $\left(\dot{\mathrm{V}}_{\mathrm{CO}_{2}}\right)$ and minute ventilation $\left(\dot{\mathrm{V}}_{\mathrm{E}}\right)$ before, during, and for $10 \mathrm{~min}$ after $1-\mathrm{min}$ bursts of cycle ergometry exercise. Ten children (range: 7 $11 \mathrm{y}$ old) and 13 adults (26-42 y old) exercised at work rates corresponding to 50 and $80 \%$ of the anaerobic or lactate threshold, $\mathbf{5 0} \%$ of the difference between anaerobic threshold and maximum $\mathrm{O}_{2}$ consumption, $100 \%$ of maximum $\mathrm{O}_{2}$ consumption, and $125 \%$ of maximum $\mathrm{O}_{2}$ consumption (125\% max). Gas exchange was measured breath by breath. Children recovered faster from high-intensity (above anaerobic threshold) exercise as judged by the time constant of single exponential curve-fits to postexercise $\mathrm{VCO}_{2}[55 \pm 10 \mathrm{~s}(1 \mathrm{SD})$ at $125 \% \cdot \max$ in children compared with $92 \pm 17 \mathrm{~s}$ at $125 \%$ max in adults; $p<0.001]$ and $\dot{V}_{\mathrm{E}}$ $(58 \pm 10 \mathrm{~s}$ at $125 \% \mathrm{max}$ in children compared with $125 \pm$ $37 \mathrm{~s}$ in adults, $p<0.001$ ). Although we found no significant difference between $\dot{V}_{C_{2}}$ and $\dot{V}_{E}$ recovery times in children, $\dot{\mathrm{V}}_{\mathrm{E}}$ was significantly slower than $\dot{\mathrm{V}}_{\mathrm{CO}_{2}}$ in adults for highintensity exercise. Moreover, recovery times in adults increased with work intensity but were independent of them in children. Whereas the $\mathrm{CO}_{2}$ costs Icalculated as total $\mathrm{CO}_{2}$ produced above baseline per unit work done $(\mathrm{mL}$. $\left.\mathrm{J}^{-1}\right)$ ] increased with work intensity in adults, no similar significant relationship was observed in children. Finally, at $125 \%$ max, the ratio of $\mathrm{CO}_{2}$ cost to $\mathrm{O}_{2}$ cost was $1.48 \pm$ 0.07 , less than the ratio in adults $(1.83 \pm 0.07, p<0.01)$. These results demonstrate marked differences in dynamic ventilatory response to short bursts of exercise reflecting maturation of both respiratory control and cellular metabolic factors. (Pediatr Res 29: 362-368, 1991)
\end{abstract}

\section{Abbreviations}

AT, anaerobic threshold

$\dot{\mathrm{V}} \mathrm{CO}_{2}, \mathrm{CO}_{2}$ production

$\dot{\mathrm{V}}_{\mathrm{E}}$, minute ventilation

$\dot{\mathrm{VO}} \mathrm{O}_{2}, \mathrm{O}_{2}$ consumption

PetCO

$\dot{\mathrm{V}} \mathrm{O}_{2}$ max, maximum $\mathrm{O}_{2}$ uptake

$\Delta$, difference between $\mathrm{VO}_{2} \max$ and $\mathrm{AT}$

$\% \max , \%$ of $\dot{\mathrm{V}}_{2} \max$

$\tau \dot{\mathrm{V}} \mathrm{CO}_{2}$, time constant for $\dot{\mathrm{V}} \mathrm{CO}_{2}$ recovery

$\tau \dot{\mathrm{V}}_{\mathrm{E}}$, time constant for $\dot{\mathrm{V}}_{\mathrm{E}}$ recovery

Correspondence and reprint requests: Dan M. Cooper, M.D., A-17 Annex, Harbor-UCLA Medical Center, 1000 West Carson Street, Torrance, CA 90509.

Supported in part by HL1 1907. Y.A. is a Research Fellow of the Joseph Drown Foundation. D.M.C. is the recipient of the Career Investigator Award, American Lung Association. S.Z. is a Research Fellow of the American Heart Association Greater Los Angeles Affiliate.
Ventilation in humans is regulated to maintain cellular homeostasis of $\mathrm{CO}_{2}$ and bicarbonate when the metabolic rate changes. The link between cellular activity and ventilation is, in large part, dependent on the distribution and transport of $\mathrm{CO}_{2}$ molecules $(1,2)$. There is evidence that the linkage between $\mathrm{V}_{\mathrm{CO}_{2}}$ and $\dot{V}_{\mathrm{E}}$ undergoes a process of maturation during growth, i.e. there is a difference between children and adults in the ventilatory response to changes in metabolic rate (3). The magnitude and mechanisms of these differences have not been fully elucidated, most likely because studying gas exchange in ways that are acceptable to children is difficult and because there are no uniform approaches to normalizing physiologic responses in subjects of widely different sizes. In this study, we employed an exercise protocol specifically designed for the behavioral characteristics of children, and the data were normalized and analyzed in a manner that facilitated comparison of children with adults.

The purpose of our study was to further test the general hypothesis that a process of maturation of the gas exchange response to exercise takes place during growth. We did this by focusing on $\mathrm{V}_{\mathrm{CO}_{2}}$ and $\dot{\mathrm{V}}_{\mathrm{E}}$ in the high-intensity exercise range [i.e. work performed above the subject's AT (4)]. In previous studies, we found that children increased $\mathrm{V}_{\mathrm{E}}$ and $\mathrm{V}_{\mathrm{CO}_{2}}$ more rapidly than adults in the transition between rest and low-intensity (belowAT) exercise (5). Little is known about ventilatory responses in the high-intensity range when respiration is regulated not only by $\mathrm{VCO}_{2}$ but also by increases in hydrogen ion concentration resulting from lactic acid production (6). Both of these coupled mechanisms (lactic acid production and reduction in $\mathrm{pH}$ ) appear to be less active in children than in adults (6-9). Thus, it seemed reasonable to hypothesize that the differences in ventilatory responses between children and adults would be greater in the high-intensity exercise range. We tested this by comparing the $\mathrm{CO}_{2}$ and ventilatory response and costs of 1-min bursts of cycle ergometery exercise at various levels of intensity in children and adults. The short-term exercise protocol was chosen because in "real life" children tend to exercise in bursts of activity, and our experience in the laboratory indicates that the tolerance of young children to more than a few minutes of high-intensity exercise is quite limited.

\section{SUBJECTS AND METHODS}

Population. Ten healthy children (six boys and four girls, aged $7-11 \mathrm{y}$, mean age $9.0 \pm 1.3 \mathrm{y}$ ) and 13 healthy adults (10 males and three females, aged $26-42 \mathrm{y}$, mean age $32.6 \pm 4.8 \mathrm{y}$ ) composed the study population. All were volunteers, had no chronic diseases, and did not smoke or use medication. The study was approved by the Human Subjects Committee of Harbor-UCLA Medical Center. Informed consent was obtained from each subject or, when appropriate, parent.

Protocols. The first protocol consisted of an incremental cycle ergometer exercise. Each subject performed a progressive exercise test to the limit of tolerance using a ramp pattern of increasing 
work rate as described previously $(4,10)$. This was used to determine the $\dot{\mathrm{VO}}_{2} \max$ and the AT. The AT corresponds to the metabolic rate $\left(\dot{\mathrm{V}}_{2}\right)$ above which anaerobic metabolism supplements aerobic energy production. Lactic acidosis then occurs, and its noninvasive determination in children has been previously described (4).

In the second protocol, the subjects performed 1-min bursts of varying intensity exercise corresponding to $50 \%$ of the AT, $80 \%$ of the AT, $50 \%$ of $\Delta, 100 \%$ max, and $125 \%$ max. A 3-min period of unloaded pedaling preceded the 1 -min exercise, and the exercise was followed by a 10 -min period of recovery (unloaded pedaling). The tests were performed in randomized order and usually required two or three separate sessions. When studies were performed on the same day, sufficient interval between studies was allowed so that all gas exchange parameters and heart rate had returned to preexercise values.

Gas Exchange Measurement. Alveolar ventilation and gas exchange were measured breath by breath. The subjects breathed through a mouthpiece connected to a low-impedance turbine volume transducer and a breathing valve with a combined dead space of $90 \mathrm{~mL}$. Oxygen and carbon dioxide concentrations were determined by mass spectrometry from a sample drawn continuously from the mouthpiece at $1 \mathrm{~mL} / \mathrm{s}$. The inspired and expired volumes and gas tensions signals underwent analog-to-digital conversion, from which $\mathrm{VO}_{2}$ (stp, dry), carbon dioxide elimination $\left(\dot{\mathrm{V}}_{\mathrm{CO}_{2}}\right.$; stp, dry), expiratory ventilation $\left(\dot{\mathrm{V}}_{\mathrm{E}}\right.$; body temperature, pressure, saturation), end tidal pressure for $\mathrm{O}_{2}$, and $\mathrm{PetCO}_{2}$ were computed on-line breath by breath as previously described (11). Included in these algorithms are corrections for dead space and breath-to-breath fluctuations in functional residual capacity. The breath-by-breath data were then interpolated to $1-\mathrm{s}$ time intervals. Heart rate was measured beat by beat by a standard lead I ECG using three electrodes placed on the chest.

Calibration of Ergometers. Careful calibration of our ergometers revealed that unloaded cycling represented $12 \mathrm{~W}$ for the adults' ergometer and $7 \mathrm{~W}$ for the children's ergometer. These values were then subtracted from the appropriate constant work rate value to correctly describe the relationship between $\dot{V} \mathrm{CO}_{2}$ or $\dot{V}_{E}$ and the external work done. To exclude the possibility of differences between the two ergometers that might have contributed to differences in the responses between the adults and children, one adult subject performed several protocols at work rates below and above the AT on both ergometers. Analysis of his data showed no difference between the two ergometers in the subject's respiratory response.

Assessment of Recovery. To determine whether the 10-min period allowed for complete recovery of the $\dot{\mathrm{V}}_{\mathrm{CO}_{2}}$ and $\dot{\mathrm{V}}_{\mathrm{E}}$, we compared the mean $\dot{\mathrm{V}}_{\mathrm{CO}_{2}}$ and $\dot{\mathrm{V}}_{\mathrm{E}}$ during the last $30 \mathrm{~s}$ of the preexercise period with the mean value of the last $30 \mathrm{~s}$ of the recovery phase. This analysis was done only for the highest work rates (i.e. $100 \% \max$ and $125 \% \max$ ) because visual inspection of the data (Figs. 1 and 2 ) showed that recovery was complete by $10 \mathrm{~min}$ for the lower-intensity exercises.

Data Analysis. $\dot{V}_{\mathrm{O}_{2}} \max$ and $A T$. $\dot{\mathrm{V}}_{2} \max$ was taken as the peak $\mathrm{VO}_{2}$ achieved by each subject before cessation of the progression exercise. The AT was measured noninvasively from the gas exchange data obtained during the progressive exercise. AT was defined as the $\dot{\mathrm{VO}}_{2}$ at which the ventilatory equivalent for $\mathrm{O}_{2}\left(\dot{\mathrm{V}}_{\mathrm{E}} / \dot{\mathrm{V}}_{2}\right)$ and end tidal pressure for $\mathrm{O}_{2}$ increased without an increase in the ventilatory equivalent for $\mathrm{CO}_{2}\left(\dot{\mathrm{V}}_{\mathrm{E}} / \dot{\mathrm{V}}_{2}\right)$ and $\mathrm{PetCO}_{2}$

Normalization. To compare $\dot{\mathrm{V}}_{2}$ responses of different-sized subjects, we used several strategies: 1 ) Work rates: The effort of each subject was scaled to his or her metabolic capability by using the physiologic landmarks AT and $\dot{\mathrm{V}}_{2}$ max rather than absolute work rate. We used "work intensity" to connote the relative work rate as $\% \mathrm{AT}, \% \Delta$, or $\% \max$. 2) $\dot{\mathrm{V}}_{\mathrm{CO}_{2}}$ and $\dot{\mathrm{V}}_{\mathrm{E}}$ per kg: The breath-by-breath $\dot{\mathrm{V}}_{\mathrm{CO}_{2}}$ and $\dot{\mathrm{V}}_{\mathrm{E}}$ data were divided by body weight for each subject, using the increase in $\dot{V}_{\mathrm{CO}_{2}}$ and $\dot{\mathrm{V}}_{\mathrm{F}}$ above baseline per $\mathrm{kg}\left(\right.$ i.e. $\left.\mathrm{VCO}_{2} \cdot \mathrm{kg}^{-1}\right)$. 3) The data were normalized to the actual work performed by finding the cumulative
$\mathrm{CO}_{2}$ cost and cumulative ventilatory cost per unit work. These were defined as the integral of $\dot{\mathrm{V}}_{2}$ and $\dot{\mathrm{V}}_{\mathrm{E}}$ over baseline values (i.e. unloaded cycling) from the onset of exercise, through the exercise period, and for $10 \mathrm{~min}$ of recovery (Fig. 1). The values of these integrals were divided by the external work done, yielding units as $\mathrm{mL}$ of $\mathrm{CO}_{2}$ (stp, dry) or respired gas (body temperature, pressure, saturation) per J. In this manner, differences (if observed) would indicate true differences in the relationship between $\dot{\mathrm{V}}_{\mathrm{CO}_{2}}$ or $\dot{\mathrm{V}}_{\mathrm{E}}$ and actual work performed.

Coupling $\mathrm{O}_{2}$ uptake and $\dot{V}_{C O}$. To gain additional insight into the physiologic mechanisms of the respiratory response, we compared the $\dot{\mathrm{VCO}}_{2}$ cost: $\mathrm{VO}_{2}$ cost ratio for all work intensities in children with those obtained in adults.

On-transient $\dot{V}_{\mathrm{CO}_{2}}$ and $\dot{V}_{E}$. With an exercise period of only 60 $s$, accurate curve-fitting of the on-transient is difficult. Therefore, we explored the $\dot{\mathrm{V}}_{\mathrm{CO}_{2}}$ and $\dot{\mathrm{V}}_{\mathrm{E}}$ relationship in the first $60 \mathrm{~s}$ by plotting $\dot{\mathrm{V}}_{\mathrm{E}}$ (above baseline) as a function of $\dot{\mathrm{V}}_{\mathrm{CO}_{2}}$ (above baseline). As noted, the breath-by-breath data are time-interpolated so that there is a data point every second. A useful noise-reducing technique in analyzing this type of data has been to superimpose and average data obtained at the same work intensity [the "groupmean" response $(12,13)]$. Thus, for the analysis of the ontransient $\mathrm{VCO}_{2}-\dot{\mathrm{V}}_{\mathrm{E}}$ response, we calculated the slope and $\mathrm{y}$ intercept of the linear regression of $\dot{\mathrm{V}}_{\mathrm{E}}$ as a function of $\dot{\mathrm{V}}_{2}$ for the group-mean data at each of the work intensities. The slopes obtained in this manner from children and adults were statistically compared.

Recovery time. The $\dot{\mathrm{V}}_{\mathrm{CO}_{2}}$ and $\dot{\mathrm{V}}_{\mathrm{E}}$ recovery times were determined by fitting the recovery data (i.e. after the 1-min work rate) with a single exponential equation (Fig. 2). The use of exponentials is based on several theoretical and experimental considerations. First, oxygen uptake kinetics at the muscle (to which $\mathrm{V} \mathrm{CO}_{2}$ and, ultimately, $\dot{V}_{E}$ kinetics are linked) are well described by exponential models $(14,15)$. Secondly, we have previously demonstrated that single-exponential equations fit the on-transient $\dot{\mathrm{V}} \mathrm{CO}_{2}$ and $\dot{\mathrm{V}}_{\mathrm{E}}$ responses to exercise (3). Thus, it seemed reasonable to use the relatively simple single-exponential model as a first attempt at modeling the recovery kinetics for $\dot{\mathrm{V}}_{\mathrm{CO}_{2}}$ and $\dot{\mathrm{V}}_{\mathrm{E}}$. Nonlinear techniques were used to calculate the parameters of the characteristic equation (16):

$$
\dot{\mathrm{V}} \mathrm{CO}_{2}(\mathrm{t})\left[\text { or } \dot{\mathrm{V}}_{\mathrm{E}}(\mathrm{t})\right]=\mathrm{A} \cdot \mathrm{e}^{-\mathrm{k} t}+\mathrm{C}
$$

where $\dot{\mathrm{V}}_{2}(\mathrm{t})$ [or $\dot{\mathrm{V}}_{\mathrm{E}}(\mathrm{t})$ ] is the value of $\dot{\mathrm{V}} \mathrm{CO}_{2}$ (or $\dot{\mathrm{V}}_{\mathrm{E}}$ ) over baseline at time $t$ (after exercise), $\mathrm{A}$ is a parameter, $\mathrm{k}$ is the rate constant, and $\mathrm{C}$ is the asymptotic baseline value (which was zero in this study because the fitting was made for data above the baseline values). The time constant $(\tau=1 / \mathrm{k})$ was used to quantify the recovery time and indicates the time required to achieve $63.2 \%$ of the difference between peak and baseline values. We analyzed the time constants of $\dot{\mathrm{V}}_{\mathrm{CO}_{2}}$ and $\dot{\mathrm{V}}_{\mathrm{E}}$ at each work intensity and compared them between children and adults. In addition, for the highest work intensity $(125 \% \max )$, we also attempted to fit the group-mean data using a two-exponential model:

$$
\dot{\mathrm{V}} \mathrm{CO}_{2}(\mathrm{t})\left[\text { or } \dot{\mathrm{V}}_{\mathrm{E}}(\mathrm{t})\right]=\mathrm{A}_{1} \cdot \mathrm{e}^{-\mathrm{k}_{1} \mathrm{t}}+\mathrm{A}_{2} \cdot \mathrm{e}^{-\mathrm{k}_{2} \mathrm{t}}+\mathrm{C}
$$

$\mathrm{PetCO}_{2}$. Petco $\mathrm{C}_{2}$ data invariably demonstrate great variability because they are influenced by many inputs (e.g. breathing frequency, tidal volume, in-laboratory stimuli, etc.). Thus, we chose to examine the group-mean responses for the highest and lowest work rates. We analyzed $120 \mathrm{~s}$ of the preexercise period, a 20 -s window surrounding the peak value, and the last $60 \mathrm{~s}$ of recovery.

Statistical analysis. Analysis of variance and appropriately modified $t$ tests were used for the statistical analysis of workintensity related differences in cumulative ventilatory and $\mathrm{CO}_{2}$ costs, time constants, and $\mathrm{PetCO}_{2}$. Paired $t$ tests were used to compare preexercise and recovery values of $\dot{\mathrm{V}}_{\mathrm{CO}_{2}}$ and $\dot{\mathrm{V}}_{\mathrm{E}}$. The slopes of the on-transient relationship between $\dot{\mathrm{V}}_{\mathrm{E}}$ and $\dot{\mathrm{V}} \mathrm{CO}_{2}$ in adults and children were compared using the $t$ statistic (17). 


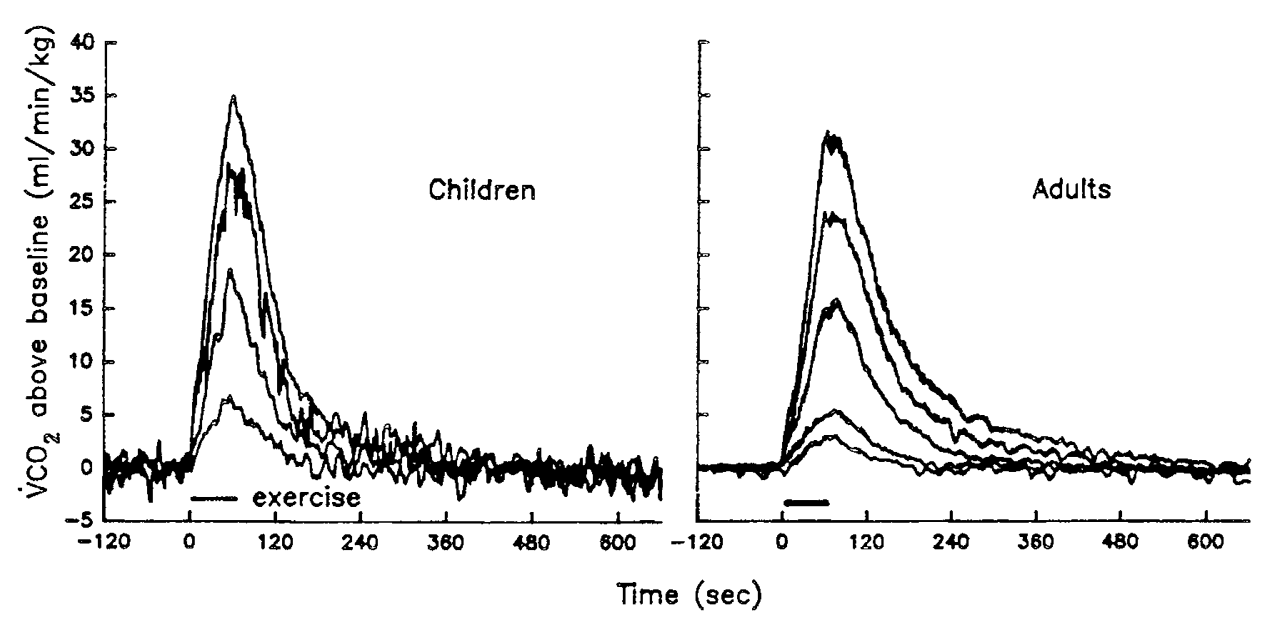

Fig. 1. $\dot{\mathrm{V}} \mathrm{CO}_{2}$ responses (above baseline 0 -W pedaling) to a 1 -min burst exercise in children and adults. The data are normalized to body weight and can be distinguished in order of work intensity [i.e. 50\% AT, 80\% AT, 50\% $\Delta, 100 \% \max , 125 \% \max$ (in children the $50 \%$ AT exercise was excluded from the study)]. Note the generally faster recovery in children.

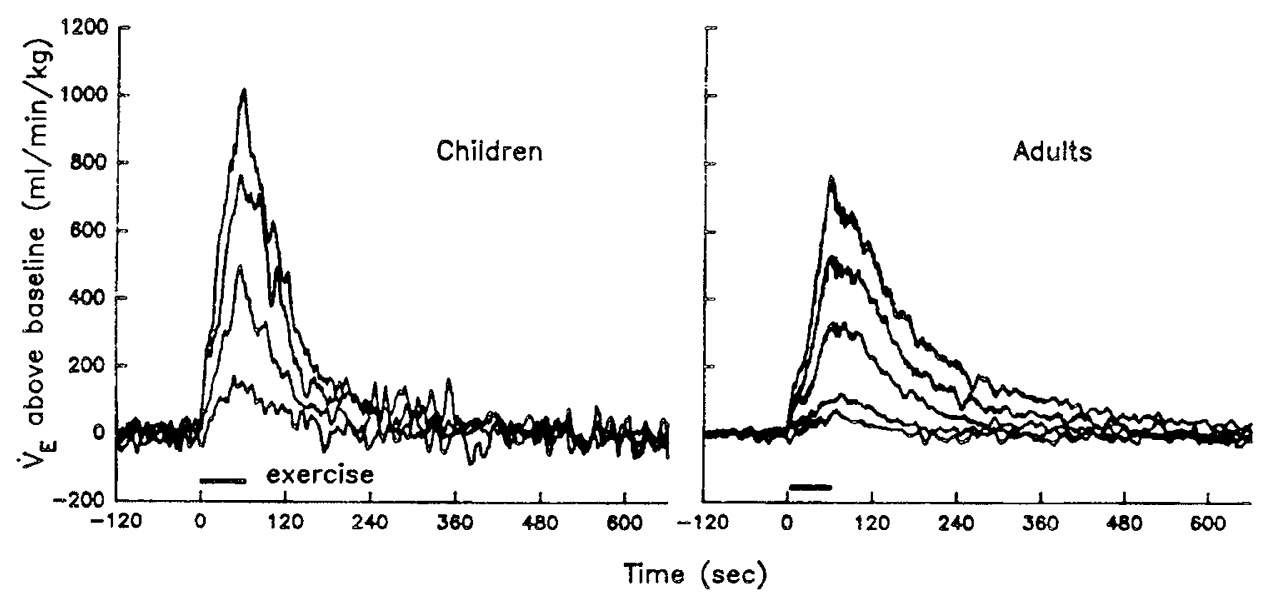

Fig. 2. $\dot{\mathrm{V}}_{\mathrm{E}}$ responses (above baseline $0-\mathrm{W}$ pedaling) to a 1-min burst exercise in children and adults. The data are normalized to body weight and can be distinguished in order of work intensity [i.e. $50 \% \mathrm{AT}, 80 \% \mathrm{AT}, 50 \% \Delta, 100 \% \max , 125 \%$ max, (in children the $50 \%$ AT exercise was excluded from the study)]. Note the faster recovery in children.

Statistical comparison of the single exponential fit to the sum of two exponentials was made using the $F$ test $(18,19)$. Statistical significance was taken at the $p<0.05$ level, and the value of the significant $t$ statistic was adjusted for the number of comparisons made. Data are expressed as mean $\pm \mathrm{SD}$ (unless otherwise stated).

\section{RESULTS}

In children, the noise-to-signal ratio for the lowest work rate ( $50 \%$ AT) was too high to permit data analysis. Thus, this work intensity was excluded from the children's study. The groupmean $\dot{\mathrm{V}}_{\mathrm{CO}_{2}}$ and $\dot{\mathrm{V}}_{\mathrm{E}}$ responses to the 1 -min exercise are shown in Figures 1 and 2.

$\dot{V O}_{2} \max$ and $A T$. There were no significant differences in the $\mathrm{VO}_{2} \mathrm{max} / \mathrm{kg}$ between the adults $\left(41.5 \pm 8.5 \mathrm{~mL} \mathrm{O} \cdot \mathrm{min}^{-1} \cdot \mathrm{kg}^{-1}\right)$ and children $\left(41.7 \pm 5.8 \mathrm{~mL} \mathrm{O} \cdot \mathrm{min}^{-1} \cdot \mathrm{kg}^{-1}\right)$. Similarly, no differences were found between the AT per $\mathrm{kg}$ in children $(24.8$ $\left.\pm 5.6 \mathrm{~mL} \mathrm{O}_{2} \cdot \mathrm{min}^{-1} \cdot \mathrm{kg}^{-1}\right)$ and adults $\left(22.6 \pm 3.5 \mathrm{~mL} \mathrm{O}_{2} \cdot \mathrm{min}^{-1}\right.$. $\mathrm{kg}^{-1}$ ). In addition, we found no significant gender-related differences of $\dot{\mathrm{V}}_{2} \mathrm{max} / \mathrm{kg}$ in either adults or children.

Cumulative $\mathrm{CO}_{2}$ cost. In both children and adults, the $\mathrm{VCO}_{2}$ at the end of the recovery period was the same as $\mathrm{V}_{\mathrm{CO}_{2}}$ before exercise at all work intensities. In adults, the $\mathrm{CO}_{2}$ cost did not change significantly for below-AT exercise (50\% AT, $0.19 \pm 0.09$ $\mathrm{mL} \cdot \mathrm{J}^{-1} ; 80 \%$ AT, $0.21 \pm 0.07 \mathrm{~mL} \cdot \mathrm{J}^{-1}$ ), but the $\mathrm{CO}_{2}$ cost for each of the above-AT exercise protocols $(50 \% \Delta, 0.26 \pm 0.04$ $100 \% \max , 0.31 \pm 0.05$; and $\left.125 \% \max , 0.34 \pm 0.05 \mathrm{~mL} \cdot \mathrm{J}^{-1}\right)$ was significantly greater than the $\mathrm{CO}_{2}$ cost of below-AT work ( $p$
$<0.05$ ). Moreover, the $\mathrm{CO}_{2}$ cost of $50 \% \Delta$ was significantly smaller than both $100 \% \max$ and $125 \% \max (p<0.05)$. In contrast, in children the cumulative $\mathrm{CO}_{2}$ cost was independent of the work intensity (for $80 \% \mathrm{AT}, 50 \% \Delta, 100 \% \max$, and $125 \%$ max the values were $0.30 \pm 0.13,0.31 \pm 0.05,0.36 \pm$ 0.09 , and $\left.0.37 \pm 0.12 \mathrm{~mL} \cdot \mathrm{J}^{-1}\right)$. Although the cumulative $\mathrm{CO}_{2}$ cost tended to be higher in children at all work intensities compared with adults, no significant differences were found.

Cumulative ventilatory cost. In children, the $\dot{\mathrm{V}}_{\mathrm{E}}$ at the end of the recovery period was the same as $\dot{V}_{E}$ before exercise for all work intensities. In adults, the preexercise and recovery values were the same except for the $100 \%$ max and $125 \%$ max protocols, where the recovery values were significantly greater by a mean of 7.9 and $8.6 \%$, respectively. In adults, the ventilatory cost did not change significantly for below-AT exercise (50\% AT, $4.29 \pm$ $1.81 \mathrm{~mL} \cdot \mathrm{J}^{-1} ; 80 \% \mathrm{AT}, 5.35 \pm 2.43 \mathrm{~mL} \cdot \mathrm{J}^{-1}$ ), but the ventilatory cost for each of the above-AT exercise protocols $(50 \% \Delta, 6.67 \pm$ $1.35 ; 100 \% \max , 7.86 \pm 1.89$; and $125 \% \max , 9.53 \pm 1.70 \mathrm{~mL}$. $\mathrm{J}^{-1}$ ) was significantly greater than the ventilatory cost of belowAT work $(p<0.05)$. Moreover, the ventilatory cost of $50 \% \Delta$ and $100 \%$ max were significantly smaller than $125 \%$ max $(p<$ $0.01)$. In children, the ventilatory costs for $80 \% \mathrm{AT}, 50 \% \Delta$, $100 \%$ max, and $125 \%$ max were $7.58 \pm 5.44,8.22 \pm 1.33,10.19$ \pm 3.28 , and $10.94 \pm 4.14 \mathrm{~mL} \cdot \mathrm{J}^{-1}$, respectively. Only the difference between the ventilatory cost of $80 \%$ AT and $125 \%$ max was statistically significant. The cumulative ventilatory cost in children was generally higher compared with adults, but the differ- 
ence was statistically significant only at the $50 \% \Delta$ work intensity $(p<0.0125)$.

Cumulative $\mathrm{CO}_{2}$ cost: $\mathrm{O}_{2}$ cost ratio (Fig. 3). In adults, there was no difference between the cost ratio for below-AT exercise, but the ratios for above-AT exercise were significantly greater than the below-AT values $(p<0.05)$. Moreover, the ratio at $50 \% \Delta$ was significantly smaller than both $100 \%$ max and $125 \% \max$ $(p<0.05)$. In children, the single below-AT result was signifi-

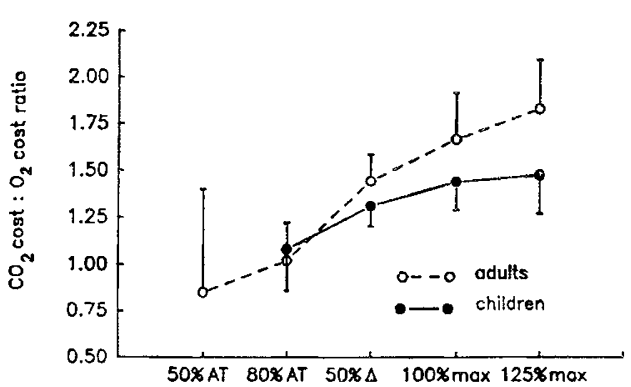

Fig. 3. Ratio of $\mathrm{CO}_{2}$ cost to $\mathrm{O}_{2}$ cost for each work intensity. Data are presented as mean $\pm \mathrm{SD}$. In both children and adults, the ratios for above-AT exercise were significantly greater than the below-AT values $(p<0.05)$. For the high-intensity exercise, the ratio increased significantly with increasing work intensity from $50 \% \Delta$ to $100 \%$ max and $125 \%$ max in adults, but no differences were observed among the ratios in children. At the highest work intensity $(125 \%$ max $)$, the ratio in adults was significantly greater than the children's value $(p<0.001)$.

Table 1. On-transient linear regression of $\dot{V}_{E}$ on $\dot{V}_{C_{2}}$

\begin{tabular}{clcc}
\hline Work intensity & Subjects & $\begin{array}{c}\text { Slope } \pm \mathrm{SEM} \\
\left(\Delta \dot{\mathrm{V}}_{\mathrm{E}} / \Delta \dot{\mathrm{V}}_{2}\right)\end{array}$ & $\begin{array}{c}\text { Y-intercept } \pm \mathrm{SEM} \\
\left(\mathrm{mL} \cdot \mathrm{min}^{-1} \cdot \mathrm{kg}^{-1}\right)\end{array}$ \\
\hline \multirow{2}{*}{$80 \% \mathrm{AT}$} & Children & $28.1 \pm 0.7^{*}$ & $-21.1 \pm 3.1$ \\
& Adults & $19.6 \pm 1.8$ & $0.2 \pm 1.8$ \\
$50 \% \Delta$ & Children & $25.5 \pm 0.4^{*}$ & $9.6 \pm 4.3$ \\
& Adults & $20.4 \pm 0.4$ & $7.1 \pm 3.3$ \\
$100 \% \max$ & Children & $25.6 \pm 0.4^{*}$ & $39.4 \pm 7.6$ \\
& Adults & $21.7 \pm 0.2$ & $2.9 \pm 3.3$ \\
$125 \% \max$ & Children & $27.8 \pm 0.2^{*}$ & $34.2 \pm 5.6$ \\
& Adults & $22.9 \pm 0.3$ & $10.3 \pm 5.0$ \\
\hline
\end{tabular}

${ }^{*} p<0.002$ for children compared with adults.

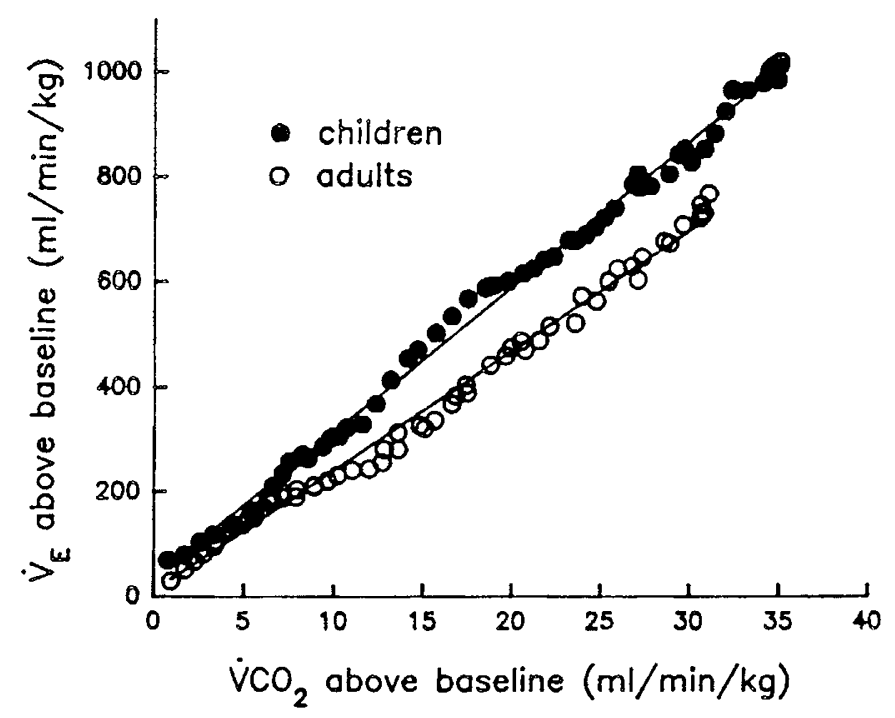

Fig. 4. $\dot{\mathrm{V}}_{\mathrm{E}}$ as a function of $\dot{\mathrm{V}}_{\mathrm{CO}_{2}}$ at the on-transient $(60 \mathrm{~s})$ of the $125 \%$ max exercise. Data represent above baseline values and are normalized to body weight. For a given increase in $\dot{\mathrm{V}} \mathrm{CO}_{2}$ children increased ventilation more than adults as reflected by a significant larger slope in children compared with adults $(p<0.001)$. (The slope values of each work intensity are shown in Table 1.)

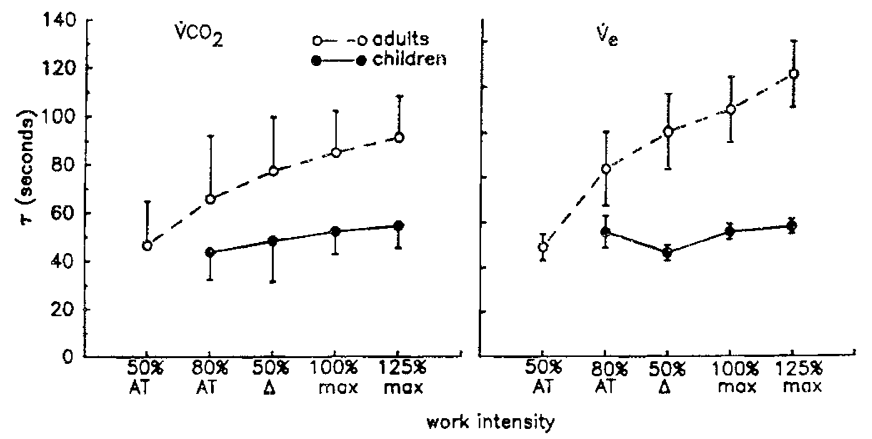

Fig. 5. Recovery time constants $(\tau)$ for $\dot{\mathrm{V}} \mathrm{CO}_{2}$ (lefi panel) and $\dot{\mathrm{V}}_{\mathrm{E}}$ (right panel). Data are presented as mean $\pm \mathrm{SD}$. The recovery times were significantly shorter in children compared with adults. In adults, $\tau \dot{\mathrm{V}} \mathrm{CO}_{2}$ increased with increasing work intensity from $50 \%$ AT to $80 \%$ AT $(p<$ $0.01)$ and from $80 \%$ AT to $50 \% \Delta(p<0.05)$, and for above-AT exercise the $\mathrm{V}_{\mathrm{CO}_{2}}$ time constant at $50 \% \Delta$ was significantly lower than $125 \%$ max. Note significantly shorter $\tau \dot{\mathrm{V}} \mathrm{CO}_{2}$ than $\tau \dot{\mathrm{V}}_{\mathrm{E}}$ in the high-intensity range for adults $(p<0.001)$. In children, no significant differences were found between $\tau \dot{\mathrm{V}} \mathrm{CO}_{2}$ and $\tau \dot{\mathrm{V}}_{\mathrm{E}}$

cantly less than each of the above-AT values, but there were no differences observed among the ratios in the high-intensity range. In the high-intensity range, the values in children were smaller than in adults, but a significant difference was found only at $125 \% \max (p<0.01)$.

On-transient relationship between $\dot{V}_{C O}$ and $\dot{V}_{l}$. The relationship between $\dot{\mathrm{V}}_{\mathrm{E}}$ and $\dot{\mathrm{V}}_{\mathrm{CO}_{2}}$ in adults and children was not the same. Children generally required greater $\dot{\mathrm{V}}_{E}$ for a given $\dot{\mathrm{V}}_{\mathrm{CO}_{2}}$ than did adults. This was reflected in the children's significantly larger slopes at all work intensities (Table 1), and is shown graphically for $125 \%$ max in Figure 4.

$\mathrm{VCO}_{2}$ recovery time (Fig. 5, left panel). In adults, $\tau \dot{\mathrm{V}} \mathrm{CO}_{2}$ increased with work intensity. There were significant increases from $50 \%$ AT to $80 \%$ AT $(p<0.01)$ and from $80 \%$ AT to $50 \%$ $\Delta(p<0.05)$. In the high-intensity range, the $50 \% \Delta$ value was significantly lower than $125 \% \max (p<0.01)$, but no other significant differences were observed. In children, $\tau \dot{\mathrm{V}} \mathrm{CO}_{2}$ was independent of work rate. Moreover, $\tau \dot{\mathrm{V}} \mathrm{CO}_{2}$ in children was significantly lower than that in adults for all the above-AT protocols $(p<0.001)$.

$\dot{V}_{E}$ recovery time (Fig. 5, right panel). In adults, $\tau \dot{\mathrm{V}}_{\mathrm{E}}$ increased with work intensity. The value at $50 \% \mathrm{AT}$ was significantly less than all other values $(p<0.01)$, and $\tau \dot{\mathrm{V}}_{\mathrm{E}}$ at $80 \%$ AT was less than $100 \%$ max and $125 \% \max (p<0.01), \tau \dot{\mathrm{V}}_{\mathrm{E}}$ at $50 \% \Delta$ was less than $125 \% \max (p<0.01)$, and there was no statistically significant difference between $\tau \mathrm{V}_{\mathrm{E}}$ of $100 \%$ max and $125 \%$ max $(p<0.01)$. In children, $\tau \dot{\mathrm{V}}_{\mathrm{E}}$ was independent of work intensity. Moreover, $\tau \dot{\mathrm{V}}_{\mathrm{E}}$ in children was significantly lower than adults for all above-AT protocols $(p<0.001)$.

In adults, $\tau \dot{\mathrm{V}}_{\mathrm{CO}_{2}}$ was significantly shorter than $\tau \dot{\mathrm{V}}_{\mathrm{E}}$ at all work rates in the high-intensity range (mean difference was $23.1 \mathrm{~s}, p$ $<0.01 ; 25.1 \mathrm{~s}, p<0.001$; and $34.1 \mathrm{~s}, p<0.001$ for $50 \% \Delta, 100 \%$ $\max$, and $125 \% \max$, respectively). By contrast, we found no significant differences between $r \mathrm{VCO}_{2}$ and $\tau \dot{\mathrm{V}}_{\mathrm{E}}$ in children.

$\mathrm{PetCO}_{2}$. The pattern of the PetCO $\mathrm{CO}_{2}$ at the highest $(125 \%$ max) and the lowest (80\% AT) work intensities is shown in Figure 6. Adults consistently showed significantly higher levels of $\mathrm{PetCO}_{2}$ in the preexercise period $(p<0.01)$. The peak $\mathrm{PetCO}_{2}$ was significantly higher in adults compared with children for both $80 \%$ AT and $125 \% \max (p<0.01)$. For low-intensity exercise, the mean preexercise-to-peak difference was $2.4 \mathrm{~mm} \mathrm{Hg}(0.3$ $\mathrm{kPa})$ in children and $3.8 \mathrm{~mm} \mathrm{Hg}(0.5 \mathrm{kPa})$ in adults. For highintensity exercise, the increases were 2.3 and $9.4 \mathrm{~mm} \mathrm{Hg}(0.3$ and $1.3 \mathrm{kPa}$ ) for children and adults, respectively. During recovery from high-intensity exercise, adults did not return to preexercise $\mathrm{PetCO}_{2}$ by the end of recovery; rather, $\mathrm{PetCO}_{2}$ was significantly lower than preexercise values $(p<0.01)$, suggesting a sustained hyperventilation. 


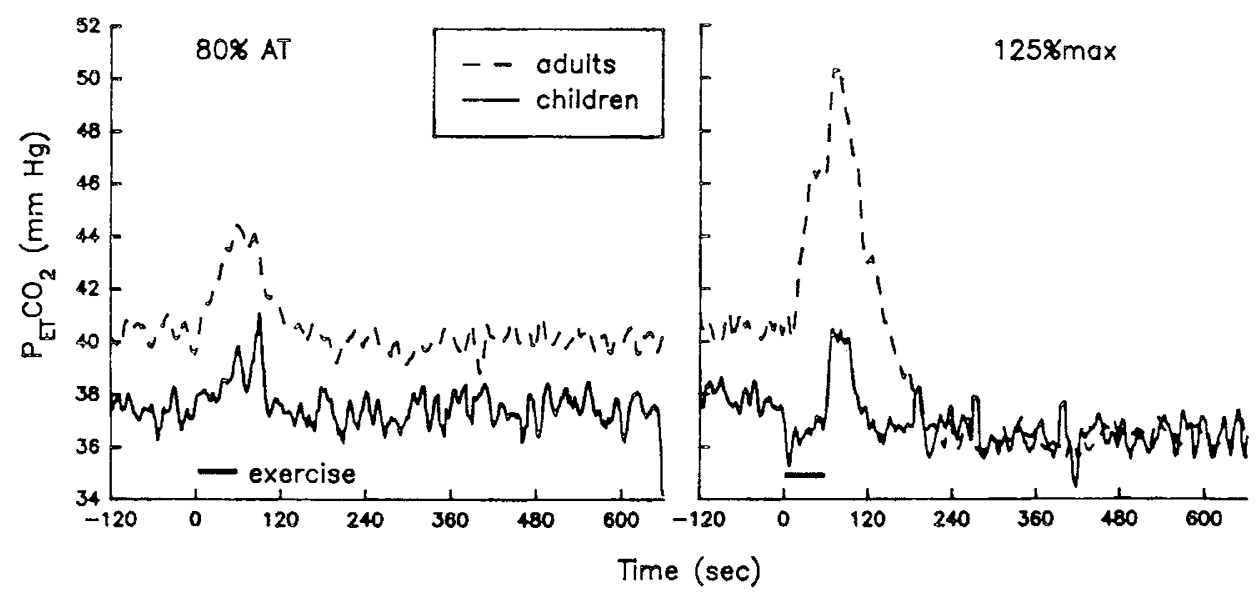

Fig. 6. The pattern of the $\mathrm{PetCO}_{2}$ at $80 \%$ AT and $125 \%$ max. The group-mean data from children and adults are shown. Adults maintained $\mathrm{PetCO}_{2}$ at higher levels than children in the preexercise period and showed higher peak values $(p<0.01)$ for both high- and low-intensity exercise. Moreover, adults did not return to preexercise values by $10 \mathrm{~min}$ after high-intensity exercise.

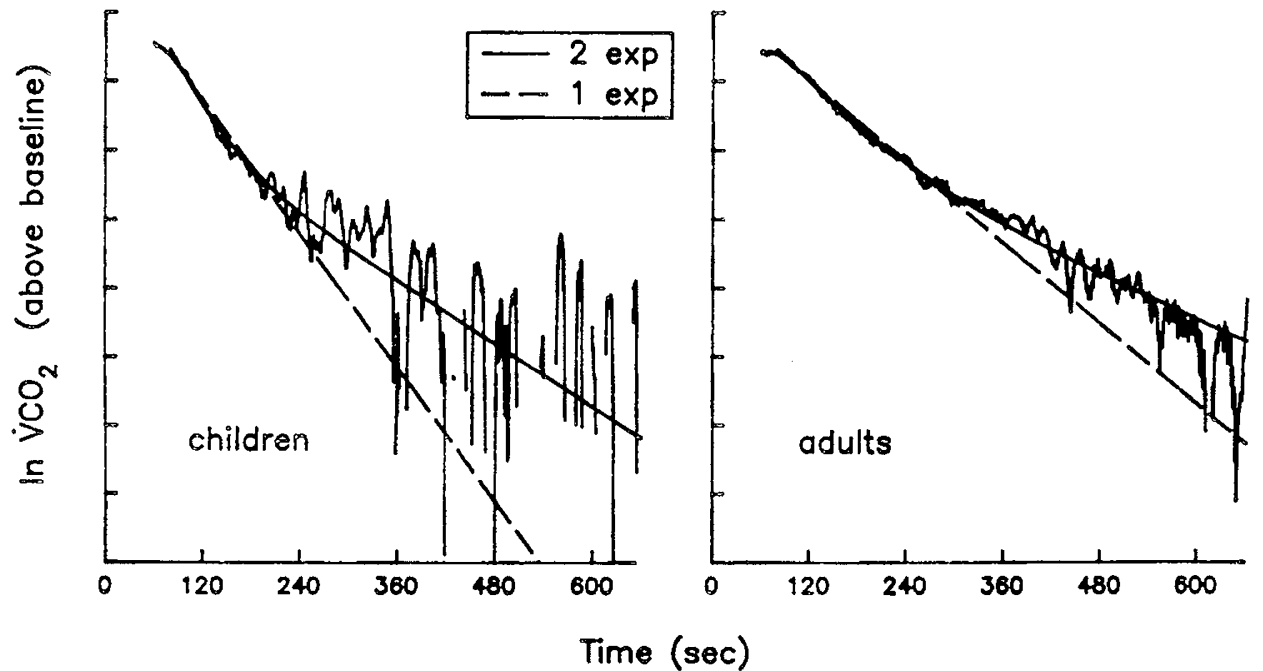

Fig. 7. Fit of one- and two-exponential equations to group-mean $\dot{\mathrm{CO}}_{2}$ recovery data in children (left panel) and adults (right panel) after $125 \%$ max work intensity. The $y$-axis represents the $\dot{\mathrm{V}} \mathrm{CO}_{2}$ above baseline on a natural logarithmic scale. Only the recovery data are shown. As can be seen, two exponentials fit the data more accurately than did a single-exponential model. Moreover, the two time constants were slower in adults $(65$ and $188 \mathrm{~s}$ ) compared with children ( 35 and $131 \mathrm{~s}$ ).

Comparison of single exponential versus sum of two exponential fits of $\dot{\mathrm{V}} \mathrm{CO}_{2}$ recovery (Fig. 7). In both adults and children, the sum of two exponentials provided a significantly better fit of the group mean data for the $\dot{\mathrm{VCO}}_{2}$ recovery than did a single exponential for the $125 \%$ max work intensity. For children, $F=$ 176 and $p<0.001$, and for adults $F=195$ and $p<0.001$.

\section{DISCUSSION}

These data demonstrate substantial differences between children and adults in the kinetics of $\dot{\mathrm{V}}_{\mathrm{CO}_{2}}$ and $\dot{\mathrm{V}}_{\mathrm{E}}$ in responses to, and recovery from, high-intensity exercise. Both the $\mathrm{CO}_{2}$ and ventilatory costs of exercise increased from low- to high-intensity exercise in adults, but these costs were largely independent of work intensity in children (only the ventilatory cost at $125 \%$ max was significantly greater than the cost at $80 \%$ AT). Adults took longer than children to recover from exercise, and $\tau \dot{\mathrm{V}} \mathrm{CO}_{2}$ and $\tau \dot{\mathrm{V}}_{\mathrm{E}}$ increased with work intensity in adults but not in children.

Significant growth-related differences in the coupling between $\dot{\mathrm{V}}_{\mathrm{E}}$ and $\dot{\mathrm{V}}_{\mathrm{CO}_{2}}$ were also noted at both the on- and off-transients of exercise. The ventilatory requirement for a given increase in $\dot{\mathrm{V}} \mathrm{CO}_{2}$ at the onset of exercise was greater in children compared with adults, and although the recovery time constants for $\mathrm{V}_{\mathrm{CO}_{2}}$ were invariably shorter than for $\dot{V}_{E}$ in adults, no statistical difference was observed in children. Finally, the pattern of $\mathrm{PetCO}_{2}$ in response to high-intensity exercise was markedly different in adults and children. It would be difficult to attribute the results of this study to a single mechanism; rather, we propose that the process of maturation of gas exchange responses involves at least two components: cellular metabolism and respiratory control.

It has long been postulated that the onset of muscle cell lactic acidosis in adults during progressive exercise is accompanied by nonlinear increases in $\mathrm{VCO}_{2}(20)$. [These observations have recently been corroborated by simultaneous measurements of gas exchange at the mouth and magnetic resonance spectroscopy of exercising muscle (21)]. Our finding in adults of increases in the $\mathrm{CO}_{2}$ cost for above-AT exercise suggests that acidosis occurred with consequent bicarbonate buffering and $\mathrm{CO}_{2}$ release above that caused by substrate oxidation. This is corroborated by the observation of increasing $\mathrm{CO}_{2}$-to- $\mathrm{O}_{2}$ cost ratio in the high-intensity range, inasmuch as the ratios we observed are too high to be explained solely by $\mathrm{O}_{2}$ consumed and $\mathrm{CO}_{2}$ produced during substrate oxidation. Thus, in adults even $1 \mathrm{~min}$ of exercise above the subject's AT likely resulted in cellular acidosis.

We did not observe similar increases in the $\mathrm{CO}_{2}$ cost or in the $\mathrm{CO}_{2}-\mathrm{to}-\mathrm{O}_{2}$ cost ratio in children during high-intensity exercise. These results suggest that children compared with adults adjust 
to high-intensity exercise with less metabolic acidosis, and, consequently, less of a $\mathrm{CO}_{2}$ load relative to $\mathrm{O}_{2}$ consumed. The data are consistent with previous observations that children achieve less metabolic acidosis during exercise than do adults (7). These results can be explained in a number of ways. First, faster $\mathrm{V}_{\mathrm{CO}_{2}}$ and $\dot{V}_{E}$ recovery in children could suggest better oxygen delivery in children compared with adults. It is possible that children are better adapted to short bursts of high-intensity exercise than are adults and, even though indices of fitness such as the $\mathrm{V}_{2} \mathrm{max} /$ $\mathrm{kg}$ or the AT/kg did not differ between the two groups, the recovery rate itself might prove to be a better task-specific estimate of fitness than are the more traditional fitness measurements. Alternatively, children may be less able than adults to sustain ATP rephosphorylation by anaerobic metabolism and, therefore, may be more dependent on aerobic energy metabolism.

Arterial $\mathrm{CO}_{2}$ tension seems to be controlled at lower levels in children compared with adults $(22-24)$. These observations were corroborated, albeit indirectly, by the measurements of $\mathrm{PetCO}_{2}$ made in this study showing that preexercise and peak-exercise values were significantly lower in children compared with adults. A lower $\mathrm{CO}_{2}$ set-point may explain, in part, the greater slopes of the $\dot{\mathrm{V}}_{\mathrm{E}}-\dot{\mathrm{V}}_{\mathrm{CO}}$ relationship that we observed at the onset of exercise: if alveolar $\mathrm{PCO}_{2}$ is lower, then greater $\dot{\mathrm{V}}_{\mathrm{E}}$ is needed to excrete a given amount of $\mathrm{CO}_{2}$. Both the magnitude of the $\dot{\mathrm{V}}_{\mathrm{E}}-\dot{\mathrm{V}}_{\mathrm{CO}_{2}}$ slopes and the growth-related decrease in them were quite similar to findings we obtained in a previous study of ventilatory responses in children and young adults (3). It is noteworthy that the $\dot{\mathrm{V}}_{\mathrm{E}}-\dot{\mathrm{V}}_{\mathrm{CO}}$ relationship was so similar even though in the earlier study the slopes were calculated from very different kinds of exercise protocols (i.e. ramp type progressive exercise) than the ones we used in the current experiments.

The data demonstrate a remarkably close coupling of $\dot{\mathrm{V}} \mathrm{CO}_{2}$ and $\dot{V}_{E}$ in children compared with adults. The rise in $\mathrm{PetCO}_{2}$ with exercise seen in both children and adults (Fig. 6) indicates that $\dot{V}_{\mathrm{CO}_{2}}$ increased more rapidly than $\dot{\mathrm{V}}_{\mathrm{E}}$, but the exercise-induced jump in $\mathrm{PetCO}_{2}$ was much smaller in children [from $37.8 \pm 0.4$ to $40.1 \pm 0.3 \mathrm{~mm} \mathrm{Hg}(5.0 \pm 0.1$ to $5.3 \pm 0.03 \mathrm{kPa})]$ compared with adults [from $40.5 \pm 0.2$ to $49.9 \pm 0.4 \mathrm{~mm} \mathrm{Hg}(5.4 \pm 0.02$ to $6.7 \pm 0.1 \mathrm{kPa})$ ], suggesting that $\dot{\mathrm{V}}_{\mathrm{E}}$ kept pace with $\mathrm{V}_{\mathrm{CO}_{2}}$ better in children than in adults during exercise and early in recovery. Although $\tau \dot{\mathrm{V}}_{\mathrm{E}}$ was significantly longer than $\tau \dot{\mathrm{V}}_{\mathrm{CO}_{2}}$ in adults after high-intensity exercise, the recovery times for $\dot{\mathrm{V}}_{\mathrm{E}}$ and $\dot{\mathrm{V}}_{\mathrm{CO}_{2}}$ were indistinguishable in the children. Although $\mathrm{PetCO}_{2}$ is only an indirect estimate of alveolar or arterial $\mathrm{PCO}_{2}$, the patterns in $\mathrm{PetCO}_{2}$ appropriately reflected the disparity in the time constants of $\dot{\mathrm{V}}_{\mathrm{E}}$ and $\dot{\mathrm{V}}_{\mathrm{CO}_{2}}$ in high-intensity exercise: in children, endrecovery $\mathrm{PetCO}_{2}$ was virtually the same as preexercise, whereas in adults a persistent hyperventilation manifested itself as significantly lower PetCO $\mathrm{C}_{2}$. Both breathing frequency and tidal volume are determinants of the $\mathrm{PetCO}_{2}$, but our experience with these variables in children during exercise is that the great variability in these signals precludes much useful data analysis from them.

There are several possible mechanisms for the differences in all $\dot{\mathrm{V}}_{\mathrm{E}}$ and $\dot{\mathrm{V}}_{2}$ recovery times observed between adults and children. One explanation is related to the distribution dynamics of $\mathrm{CO}_{2}$-bicarbonate in the body. It has been suggested that at least three kinetically distinct compartments exist with rate constants ranging from several minutes to close to an hour $(25,26)$. Although tracer estimates of $\mathrm{CO}_{2}$ /bicarbonate stores are similar in adults compared with children at rest (27), it appears that children store less $\mathrm{CO}_{2}$ during exercise than do adults (28). We postulate that more $\mathrm{CO}_{2}$ was stored in the slower exchanging "compartments" (e.g. adipose tissue) during high-intensity exercise in adults compared with children. In other words, the metabolically produced $\mathrm{CO}_{2}$ is stored intramuscularly or in adjacent adipose tissue $\left(\mathrm{CO}_{2}\right.$ is quite soluble in lipids) and slowly released to the central circulation. Consistent with this notion is our finding that the time constants for $\dot{\mathrm{V}}_{\mathrm{CO}_{2}}$ (and $\dot{\mathrm{V}}_{\mathrm{E}}$, which had not returned to baseline by $10 \mathrm{~min}$ after the highest intensity exercise) were significantly longer in the adults (Fig. 5).

We wondered, therefore, whether or not the recovery data might be better fit by models more complex than the simple single-exponential equation that has traditionally been used for such analyses. The finding, for example, of additional exponentials would provide evidence for the existence of additional more slowly exchanging pools or compartments $(19,29)$. As seen in Figure 7, the two-exponential model provided a better fit than did the single exponential model for high-intensity exercise in both children and adults. The observation of a second, slower, exponential component suggests that more precise analysis of $\dot{\mathrm{V}} \mathrm{CO}_{2}$ and $\dot{\mathrm{V}}_{\mathrm{E}}$ recovery from even short-term exercise may require longer periods of recovery than the $10 \mathrm{~min}$ employed in our study.

The relative hyperventilation in adults (Fig. 6) might reflect stimulation of respiratory chemoreceptors by the washout of hydrogen ions from cellular sites of anaerobic metabolism during exercise. Alternatively, we speculate that maturation of $\mathrm{CO}_{2^{-}}$ bicarbonate distribution dynamics could also explain the relative hyperventilation observed in adults and, to a lesser extent, in children in the recovery phase. The site of respiratory chemoreceptors ("central" in the midbrain; "peripheral" in the carotid bodies) may be associated with pools that exchange $\mathrm{CO}_{2}$ more slowly than the central circulation. Consequently, a disequilibrium could exist after exercise in which the respiratory control centers are sensing sufficiently high levels of $\mathrm{CO}_{2}$ (or $\mathrm{CO}_{2}$-related changes in $\mathrm{pH}$ ) to stimulate ventilation. The increased ventilation observed in adults during recovery from high-intensity exercise results in a more rapid washout of $\mathrm{CO}_{2}$ from the central circulation than from the physical location of the respiratory sensors.

Short bursts of high-intensity exercise proved useful in identifying some of the ways in which ventilatory control changes during growth. Previous work in our laboratory in adult patients with heart and lung disease $(30,31)$ demonstrated that the dynamic responses to exercise become measurably abnormal. Short-term exercise with the focus on gas exchange dynamics during recovery would be advantageous particularly in the chronically ill child or adult in that the stress imposed is limited and mimics patterns of activity encountered in real life. This approach may have a role in elucidating pathophysiologic mechanisms of chronic lung, heart, or metabolic diseases in children by enabling the clinician to noninvasively follow changes in cardiorespiratory function over time or after a particular therapeutic intervention.

\section{REFERENCES}

1. Phillipson EA, Bowes G, Townsend ER, Duffin J, Cooper JD 1981 Role of metabolic $\mathrm{CO}_{2}$ production in ventilatory response to steady-state exercise. $\mathbf{J}$ Clin Invest 68:768-774

2. Wasserman DH, Whipp BJ 1983 Coupling of ventilation to pulmonary gas exchange during nonsteady-state in men. J Appl Physiol 54:587-593

3. Cooper DM, Kaplan M, Baumgarten L, Weiler-Ravell D, Whipp BJ, Wasserman $\mathrm{K} 1987$ Coupling of ventilation and $\mathrm{CO}_{2}$ production during exercise in children. Pediatr Res 21:568-572

4. Wasserman K, Whipp BJ, Koyal SN, Beaver WL 1973 Anaerobic threshold and respiratory gas exchange during exercise. J Appl Physiol 35:236-243

5. Cooper DM, Weiler Ravell D, Whipp BJ, Wasserman K 1984 Aerobic parameters of exercise as a function of body size during growth in children. $J \mathrm{Appl}$ Physiol 56:628-634

6. Wasserman K 1986 Anaerobiosis, lactate, and gas exchange during exercise: the issues. Fed Proc 45:2904-2909

7. Matejkova J, Kiprivova Z, Placheta Z 1980 Changes in acid-base balance after maximal exercise. In: Placheta $Z$ (ed) Youth and Physical Activity. JE Purkyne University, Brno, Czechoslovakia, pp 191-199

8. Bar-Or O 1983 Pediatric Sports Medicine for the Practioner. Springer-Verlag, New York, pp 1-65

9. Eriksson BO 1980 Muscle metabolism in children-a review. Acta Paediatr Scand 283:20-28

10. Whipp BJ, Davis JA, Torres F, Wasserman K 1981 A test to determine parameters of aerobic function during exercise. J Appl Physiol 50:217-221

11. Beaver WL, Lamarra N, Wasserman K 1981 Breath-by-breath measurement of true alveolar gas exchange. J Appl Physiol 51:1662-1675

12. Lamarra N 1982 Ventilatory control, cardiac output, and gas exchange dynamics during exercise transients in man. Thesis, UCLA, Los Angeles 
13. Cooper DM, Berry C, Lamarra N, Wasserman K 1985 Kinetics of oxygen uptake and heart rate at onset of exercise in children. J Appl Physiol 59:211217

14. Piiper J, Di Prampero PE, Cerretelli P 1968 Oxygen debt and high energy phosphates in gastrocnemius muscle of the dog. Am J Physiol 215:523-531

15. Whipp BJ, Mahler M 1980 Dynamics of pulmonary gas exchange during exercise. In: West $J$ (ed) Pulmonary Gas Exchange. Academic Press, New York, pp 33-96

16. Jennrich R 1988 Nonlinear regression. In: Dixon WJ (ed) BMDP Statistical Software Manual. University of California Press, Berkeley, pp 857-884

17. Edwards AL 1976 An Introduction to Linear Regression and Correlation. WH Freeman and Co, San Francisco

18. Beck JV, Arnold KJ 1977 Parameter Estimation. Wiley, New York

19. Landaw EM, DiStefano JJ 1984 Multiexponential, multicompartmental, and noncompartmental modelling. Part 2-data analysis and statistical consideration. Am J Physiol 246:R665-R667

20. Wasserman K, Whipp BJ 1983 Coupling of ventilation and pulmonary gas exchange during nonsteady-state work in man. J Appl Physiol 54:587-593

21. Systrom D, Kanarek D, Kohler S, Kazemi H $1990{ }^{31} \mathrm{P}$ Nuclear magnetic resonance spectroscopy of the anaerobic threshold in humans. J Appl Physiol 68:2060-2066

22. Brady JP, Cotton EC, Tooley WH 1964 Chemoreflexes in the newborn infant: effect of $100 \%$ oxygen on heart rate and ventilation. J Physiol (Lond) 172:332-334

23. Brady JP, Ceruti E 1966 Chemoreceptor reflexes in the newborn infant: effect of varying degrees of hypoxia on heartrate and ventilation in a warm environment. J Physiol (Lond) 184:631-645

24. Springer C, Cooper DM, Wasserman K 1988 Evidence that maturation of the peripheral chemoreceptors is not complete in childhood. Respir Physiol $74: 55-64$

25. Irving CS, Wong WW, Shulman RJ, Smith E, Klein PD $1983\left[{ }^{13} \mathrm{C}\right]$ bicarbonate kinetics in humans: intra- vs. interindividual variations. Am J Physiol 245:R 190-R202

26. Barstow TJ, Cooper DM, Sobel E, Landaw E, Epstein S 1990 Influence of increased metabolic rate on ${ }^{13} \mathrm{C}$-bicarbonate washout kinetics. Am J Physiol 259:R163-R174

27. Armon Y, Cooper DM, Springer C, Barstow TJ, Rahimizadeh E, Landaw E, Epstein S 1990 Oral ${ }^{13} \mathrm{C}$-bicarbonate measurement of $\mathrm{CO}_{2}$ stores and dynamics in children and adults. J Appl Physiol 69:1754-1760

28. Springer C, Barstow TJ, Cooper DM 1989 Effect of hypoxia on ventilatory control during exercise in children and adults. Pediatr Res 25:285-290

29. Landaw EM, DiStefano JJ 1984 Multiexponential, multicompartmental, and noncompartmental modelling. Part 1 -methodological limitations and physiologic interpretations. Am J Physiol 246:R651-R664

30. Sietsema KE, Cooper DM, Perloff JK, Child JS, Rosove JH, Wasserman K, Whipp BJ 1988 Control of ventilation during exercise in patients with central venous-to-systemic arterial shunts. J Appl Physiol 64:234-242

31. Nery LE, Wasserman K, Andrews JD, Huntsman DJ, Hansen JE, Whipp BJ 1982 Ventilatory and gas exchange kinetics in chronic obstructive lung disease. J Appl Physiol 53:1594-1602 